\title{
Особенности волноводной рекомбинации в лазерных структурах с асимметричными барьерными слоями
}

\author{
(С) Ю.С. Полубавкина ${ }^{1}$, Ф.И. Зубов ${ }^{1,2}$, Э.И. Моисеев ${ }^{1}$, Н.В. Крыжановская ${ }^{1,2}$, М.В. Максимов ${ }^{1,2}$, \\ E.C. Семенова ${ }^{3}$, К. Yvind ${ }^{3}$, Л.В. Асрян ${ }^{4}$, А.Е. Жуков ${ }^{1,2}$ \\ ${ }^{1}$ Санкт-Петербургский национальный исследовательский Академический университет Российской академии наук, \\ 194021 Санкт-Петербург, Россия \\ ${ }^{2}$ Санкт-Петербургский политехнический университет Петра Великого, \\ 195251 Санкт-Петербург, Россия \\ ${ }^{3}$ DTU Fotonik, Technical University of Denmark, \\ Kgs. Lyngby, DK-2800, Denmark \\ ${ }^{4}$ Virginia Polytechnic Institute and State University, \\ Blacksburg, Virginia 24061, USA \\ E-mail: polubavkina@mail.ru
}

(Получена 28 июня 2016 г. Принята к печати 3 июля 2016 г.)

\begin{abstract}
Методом сканирующей ближнепольной оптической микроскопии исследовано пространственное распределение интенсивности излучения, возникающего при больших уровнях накачки (до $30 \mathrm{kA} / \mathrm{cm}^{2}$ ) вследствие рекомбинации в волноводном слое лазерной структуры GaAs/AlGaAs с асимметричными барьерными слоями GaInP и AlGaInAs. Обнаружено, что в таком лазере волноводная люминесценция, в целом менее интенсивная по сравнению с наблюдаемой в аналогичном лазере без асимметричных барьеров, распределена в волноводе неравномерно - максимум распределения сдвинут к р-эмиттеру. Это может быть объяснено способностью барьера GaInP, примыкающего к квантовой яме со стороны $n$-эмиттера, подавлять транспорт дырок.
\end{abstract}

DOI: 10.21883/FTP.2017.02.44116.8361

\section{1. Введение}

Выброс носителей заряда из активной области полупроводникового лазера в барьерные (волноводные) слои при больших токах накачки и/или повышенных температурах $[1,2]$ является одной из причин, ограничивающих характеристики мощных лазерных диодов. Частично преодолеть проблемы, связанные с заполнением лазерного волновода носителями заряда, позволяет использование асимметричных барьерных слоев (АБС) [3]. В [4] было установлено снижение внутренних потерь и повышение температурной стабильности в лазерах на структурах GaAs/AlGaAs c АБС, а в [5] было показано, что использование АБС приводит к подавлению нелинейности ватт-амперной характеристики $(\mathrm{BTAX})$ и, таким образом, к снижению рабочего тока. В [5] также было показано, что лазерные структуры с АБС характеризуются при повышенных температурах заметным снижением интенсивности волноводной люминесценции по сравнению с аналогичными гетероструктурами без АБС. В то же время следует отметить, что улучшение лазерных характеристик в реализованных к настоящему времени лазерах с АБС оказывается не столь значительным, как это ожидается для случая полной блокировки биполярного заполнения лазерного волновода [6,7].

Длительное время практически единственным методом экспериментального исследования заполнения волноводных состояний в работающем лазере было измерение спектров электролюминесценции через окно в верхнем контакте [1]. Недавно было показано, что заметная интенсивность полосы излучения, соответ- ствующей рекомбинации носителей заряда в материале волновода, наблюдается и в спектрах, записанных с торца лазерного диода в дальнем поле. В частности, излучение из AlGaAs-волновода наблюдалось в таких спектрах мощных лазеров на основе квантовых ям InGaAs спектрального диапазона 1.01-1.07 мкм [8-10].

Недостатком перечисленных методов является невозможность локализации пространственной области, в которой возникает волноводная люминесценция. В то же время весьма мощным инструментом для исследования локальных оптических свойств резонаторов, в том числе лазерных, является метод сканирующей ближнепольной оптической микроскопии (СБОМ) (см., например, [11]). В настоящей работе методом СБОМ был исследован пространственный характер распределения волноводной люминесценции в лазерных структурах $\mathrm{GaAs} / \mathrm{AlGaAs,} \mathrm{в}$ том числе содержащих АБC GaInP и AlGaInAs. Показано, что пространственное распределение является асимметричным с максимумом, сдвинутым в прилегающую к $p$-эмиттеру область волновода. Это может быть объяснено способностью GaInP, примыкающего к квантовой яме со стороны $n$-эмиттера, подавлять транспорт дырок.

\section{2. Лазер с асимметричными барьерными слоями}

В лазерных структурах с AlGaAs-волноводом слои, обладающие заметной асимметрией высоты потенциального барьера для носителей заряда различного знака, могут быть созданы на основе GaInAsP (для использования в качестве барьерного слоя со стороны $n$-эмиттера) и на 


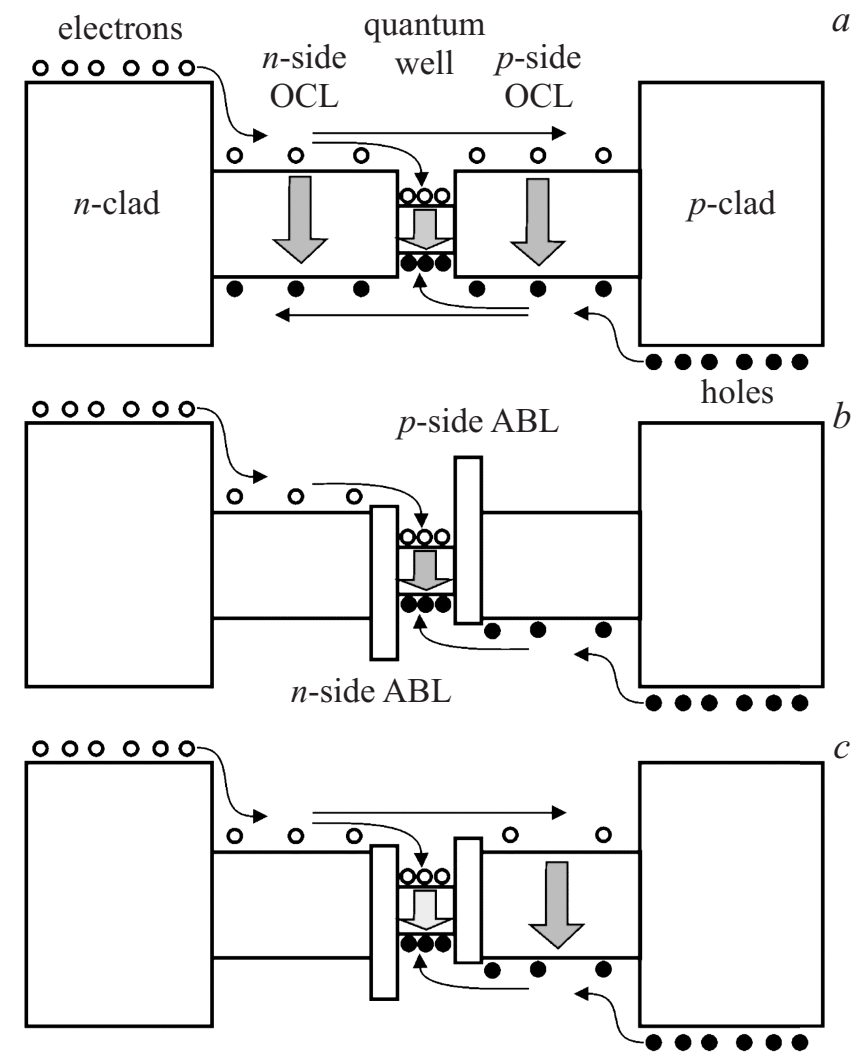

Pис. 1. Схематическое изображение зонной диаграммы, транспорта (узкие стрелки) и рекомбинации (широкие стрелки) носителей заряда в лазерной структуре традиционной конструкции (a), с АБС, полностью блокирующими транспорт носителей $(b)$, и с АБС, блокирующими только транспорт дырок $(c)$.

основе AlGaAsSb или AlGaInAs (для барьерного слоя со стороны $p$-эмиттера) [12,13]. Принцип действия лазера с АБС становится понятен из рис. $1, a, b$, на котором схематически изображены зонная диаграмма и процессы транспорта и рекомбинации носителей в лазерной гетероструктуре традиционной конструкции (рис. 1,a) и в структуре, содержащей два АБС (asymmetric barrier layers, ABLs) - по одному с каждой стороны активной области (рис. $1, b)$. В первом случае электроны и дырки имеют возможность при достаточно высоком уровне инжекции из эмиттеров (cladding layers, clads) заполнять весь лазерный волновод (optical confinement layer, OCL). Это приводит к возникновению дополнительного по отношению к их рекомбинации в квантовой яме (quantum well, QW) канала рекомбинации через состояния волновода. Это и является в конечном счете причиной ухудшения температурной стабильности характеристик лазера и отклонения ВТАХ от линейного закона. В противоположность этому в лазере с идеальными асимметричными барьерными слоями, каждый из которых обеспечивает полную блокировку транспорта одного из типов носителей заряда, рекомбинация возможна только в активной области, поскольку расположенный со стороны $n$-эмиттера барьерный слой препятствует проникновению дырок в примыкающую к $n$-эмиттеру область волновода, а барьерный слой со стороны $p$-эмиттера - проникновению электронов в часть волновода, примыкающую к $n$-эмиттеру.

В том же случае, если только один из АБС (например, со стороны $n$-эмиттера, как это показано на рис. $1, c)$ обладает способностью блокировать транспорт носителей заряда (в данном случае дырок), тогда как второй АБС подавляет транспорт носителей другого знака в недостаточной степени, электронно-дырочная рекомбинация может иметь место в части волноводного слоя (в данном случае в области, примыкающей к $p$-эмиттеру). Отметим, что характер пространственного распределения волноводной рекомбинации в лазерах с АБС ранее не изучался. Его исследование позволит получить информацию о способности реализуемых на практике АБС блокировать транспорт инжектируемых носителей заряда.

\section{3. Описание эксперимента}

В настоящей работе нами были исследованы две лазерные структуры, синтезированные на подложках $n^{+}$-GaAs (100) методом газофазной эпитаксии из металлоорганических соединений. Первая, далее обозначенная как REF-структура, представляет собой структуру c квантовой ямой $\mathrm{GaAs} / \mathrm{Al}_{0.2} \mathrm{Ga}_{0.8} \mathrm{As}$ толщиной $8 \mathrm{HM}$, помещенной в середину прямоугольного волновода $\mathrm{Al}_{0.2} \mathrm{Ga}_{0.8} \mathrm{As}$ общей толщиной 0.8 мкм, ограниченного $n$ - и $p$-эмиттерами $\mathrm{Al}_{0.4} \mathrm{Ga}_{0.6} \mathrm{As}$. Вторая, обозначенная как LAB-структура, дополнительно по отношению к REF-структуре имеет два асимметричных барьерных слоя толщиной по 7 нм, размещенные по обеим сторонам квантовой ямы. В качестве АБС, расположенного со стороны n-эмиттера, использован слой $\mathrm{Ga}_{0.55} \mathrm{In}_{0.45} \mathrm{P}$, создающий для дырок потенциальный барьep высотой 240 мэВ, а для электронов высотой 3 мэВ. В качестве АБС со стороны $p$-эмиттера использован $\mathrm{Al}_{0.42} \mathrm{Ga}_{0.38} \mathrm{In}_{0.2} \mathrm{As}$, дающий барьер для электронов высотой 78 мэВ и для дырок высотой 35 мэВ.

Из эпитаксиальных пластин были изготовлены полосковые диоды со сколотыми гранями с шириной апертуры 50 мкм и различной длиной резонатора, которые были с помощью индия напаяны $p$-стороной на медные теплоотводы (рис. 2,a). Ранее исследованные [5] диоды с длиной резонатора 2 мм работали при комнатной температуре в режиме лазерной генерации через основной оптический переход квантовой ямы. При этом в лазере на основе REF-структуры для достижения выходной мощности 8 Вт требовался рабочий ток $14.8 \mathrm{~A}$, тогда как в лазере на основе LAB-структуры рабочий ток был снижен до 8.1 А благодаря подавлению паразитной рекомбинации в волноводном слое и приближению ВТАХ к линейной. 

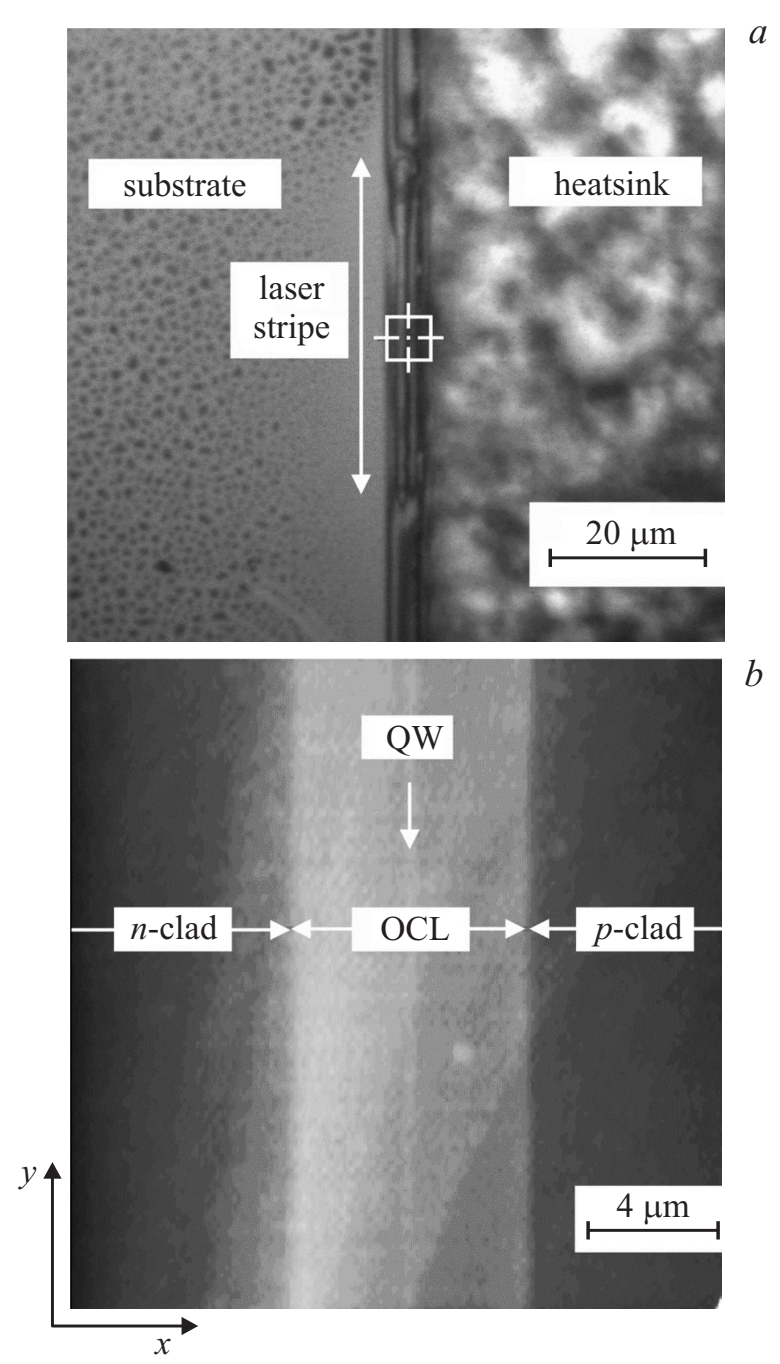

Рис. 2. Общий вид лазерного полоска (laser stripe) на теплоотводе (heatsink), снятый с помощью видеокамеры при токе накачки $1.2 \mathrm{~A}(a)$ и АCM-изображение участка зеркала в области волновода $(\mathrm{OCL})$ и активной области $(\mathrm{QW})(b)$ для REF-структуры.

В настоящей работе мы исследуем диоды длиной $\sim 100$ мкм, в которых переход в режим лазерной генерации подавлен вплоть до больших плотностей тока накачки, что позволяет выявить особенности заполнения волноводного слоя носителями заряда. Все измерения проводились при комнатной температуре. Спектры электролюминесценции в дальнем поле исследовались с помощью монохроматора Spectral Products DK 480 и InGaAs-фотодиода Teledyne Judson. Накачка осуществлялась импульсами продолжительностью 400 нс, следующими с частотой 150 Гц.

Исследования поверхности скола (лазерного зеркала) методом атомно-силовой микроскопии (АСМ) в полуконтактном режиме, а также пространственного распределения интенсивности излучения, попадающего в выбранный спектральный диапазон, методом СБОМ были выполнены с помощью установки ИНТЕГРА Спек- тра (НТ-МДТ) с использованием кантилеверного зонда SNOM_NC c апертурой 100 нм. Детектирование оптического сигнала осуществлялось с помощью высокоапертурного объектива Mitutoyo × 100, конфокального спектрометра (MS5204i, Sol Instruments) и ПЗС-камеры iVAC (Andor). Для минимизации тепловых дрейфов и стабилизации картины излучения измерения СБОМ выполнялись на диодах, накачиваемых импульсами тока длительностью 400 нс с частотой 1 кГц. Исследовался участок поверхности зеркала, взятый вблизи центра лазерного полоска (на рис. 2, $a$ область сканирования отмечена квадратом).

\section{4. Результаты}

Исследования лазерных зеркал методом АСМ не выявили каких-либо особенностей в LAB-структуре по отношению к REF-структуре. На приведенном на рис. $2, b$ изображении участка зеркала REF-структуры наблюдается высокая степень планарности интерфейсов волновод-эмиттер, а также квантовой ямы. Шероховатость сколов в пределах лазерного волновода и примыкающих к нему участков эмиттеров не превышает 3 нм.

На рис. 3 показаны спектры электролюминесценции в дальнем поле для диодов длиной $\sim 100$ мкм. В дополнение к линии люминесценции с длиной волны $\sim 850 \mathrm{Hм}$, обусловленной рекомбинацией носителей заряда через основной оптический переход квантовой ямы и обозначенной QW GS, с ростом плотности тока накачки примерно до $J=3 \mathrm{\kappa A} / \mathrm{cm}^{2}$ в спектрах возникает линия около 790 нм (QW ES), связанная с возбужденным оптическим переходом в квантовой яме, а начиная примерно с $10 \mathrm{\kappa A} / \mathrm{cm}^{2}$ еще одна линия (OCL) вблизи 750 нм, возникновение которой обусловлено рекомбинацией носителей заряда, заполняющих лазерный волновод. Как видно,

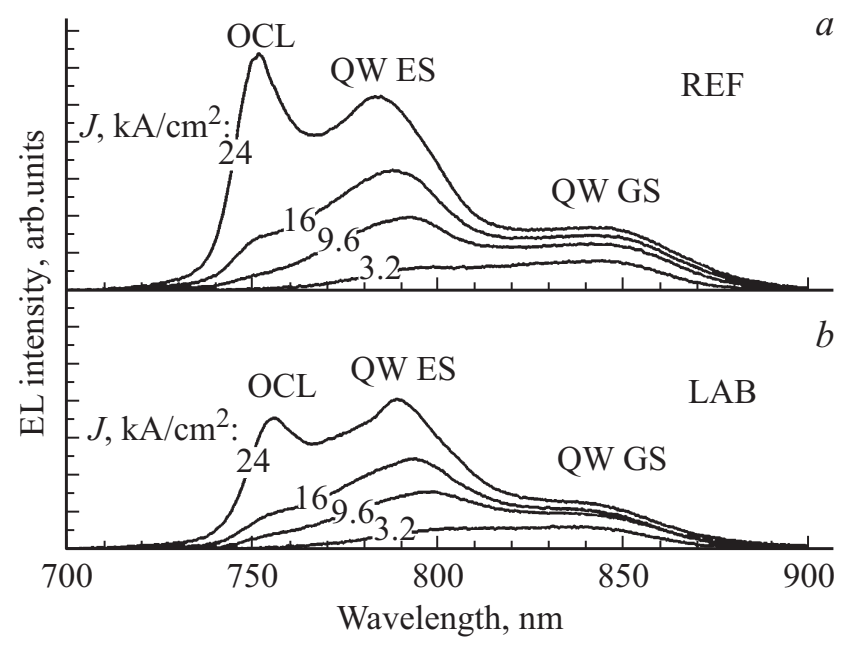

Рис. 3. Спектры электролюминесценции (EL) в дальнем поле структур REF $(a)$ и LAB (b) при различных уровнях инжекции. Пики люминесценции соответствуют основному (QW GS), возбужденному (QW ES) переходам квантовой ямы и рекомбинации в волноводном слое (OCL). 


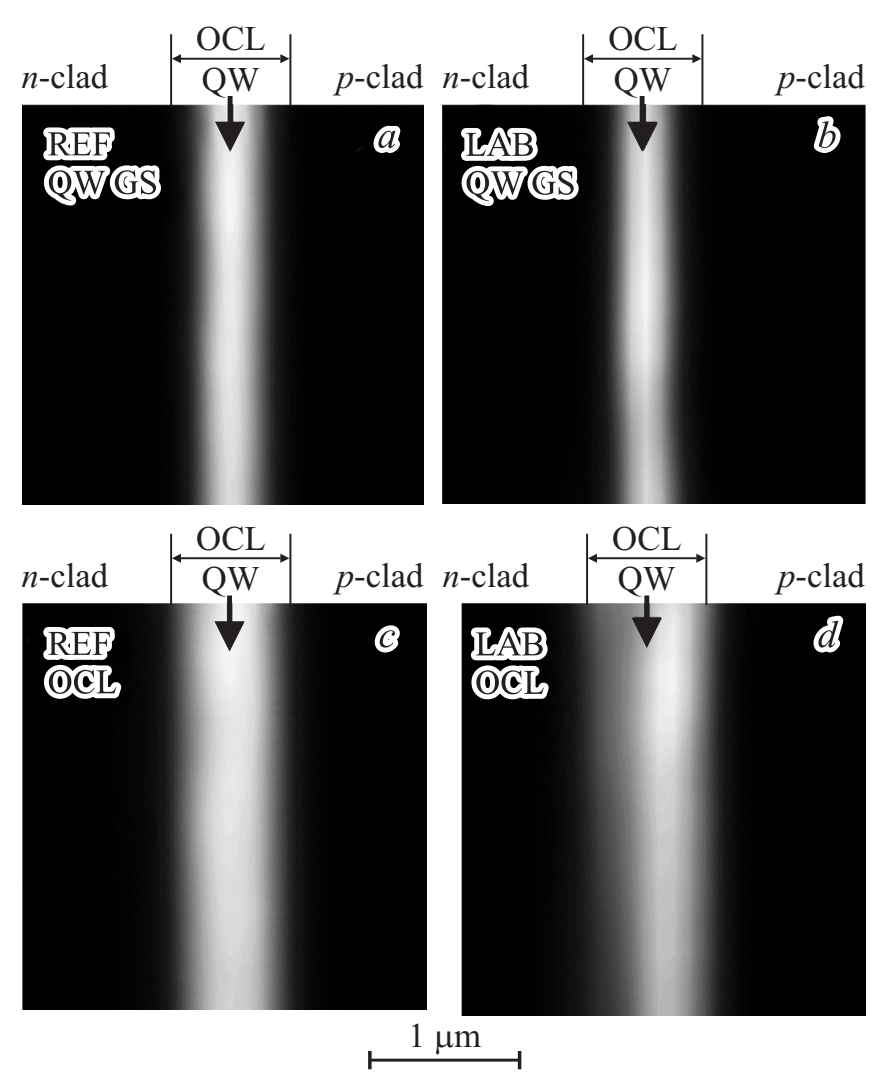

Рис. 4. Карта СБОМ (x-y-скан) в спектральном диапазоне основного перехода квантовой ямы $(a, b)$ и волноводной люминесценции $(c, d)$ для структур $\operatorname{REF}(a, c)$ и $\mathrm{LAB}(b, d)$. Плотность тока накачки 24 кА/ $\mathrm{cm}^{2}$.

при комнатной температуре линия волноводной электролюминесценции по отношению к другим спектральным линиям оказывается в структуре с асимметричными барьерами (рис. $3, b$ ) менее интенсивной по сравнению с наблюдаемой для REF-структур (рис. 3,a). Ранее такое поведение наблюдалось в спектрах электролюминесценции, измеренных при $70^{\circ} \mathrm{C}$.

Спектры электролюминесценции, записанные в ближнем поле методом СБОМ, носят качественно такой же характер. Однако, как оказалось, относительная интенсивность спектральных компонент зависит от пространственной координаты области измерения. На рис. 4 показаны карты пространственного распределения $(x-y$-скан) интенсивности электролюминесценции для обеих структур, полученные методом СБОМ при накачке $24 \kappa \mathrm{A} / \mathrm{cm}^{2}$ и выполненные в двух спектральных диапазонах, один из которых соответствует основному переходу квантовой ямы (844-856 нм), а второй — волноводной люминесценции (742-756 нм). Размер представленных участков поверхности скола, захватывающих активную область и лазерный волновод, составляет $3 \times 3$ мкм. Как видно, распределение волноводной электролюминесценции в ближнем поле в LAB-структуре (рис. 4,d) носит асимметричный характер, с максимумом, сдвинутым ближе к $p$-эмиттеру.
B то же время в REF-структуре (рис. 4,c) волноводная люминесценция распределена симметрично относительно центра волновода. Такой же симметричный характер носит и пространственное распределение излучения из квантовой ямы в обеих структурах (рис. 4, $a, b$ ).

Более детальную информацию позволяет получить анализ профилей интенсивности поперек лазерного волновода $(x$-скан). Распределения интенсивности излучения, соответствующего основному переходу в квантовой яме (рис. 5), в обеих структурах практически совпадают - они имеют максимум в середине волновода (с точностью \pm 0.02 мкм) и характеризуются одинаковой пространственной шириной на половине высо-

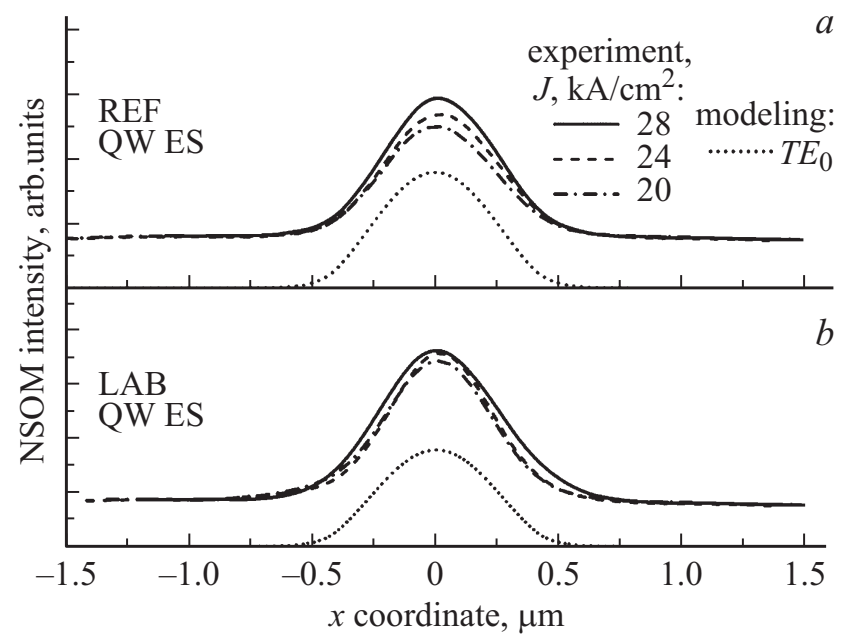

Рис. 5. Профили интенсивности сигнала СБОМ ( $x$-скан) при различных уровнях накачки в спектральном диапазоне основного перехода квантовой ямы для структур REF $(a)$ и $\mathrm{LAB}(b)$. Точечными линиями показан расчет профиля моды в диэлектрическом волноводе.

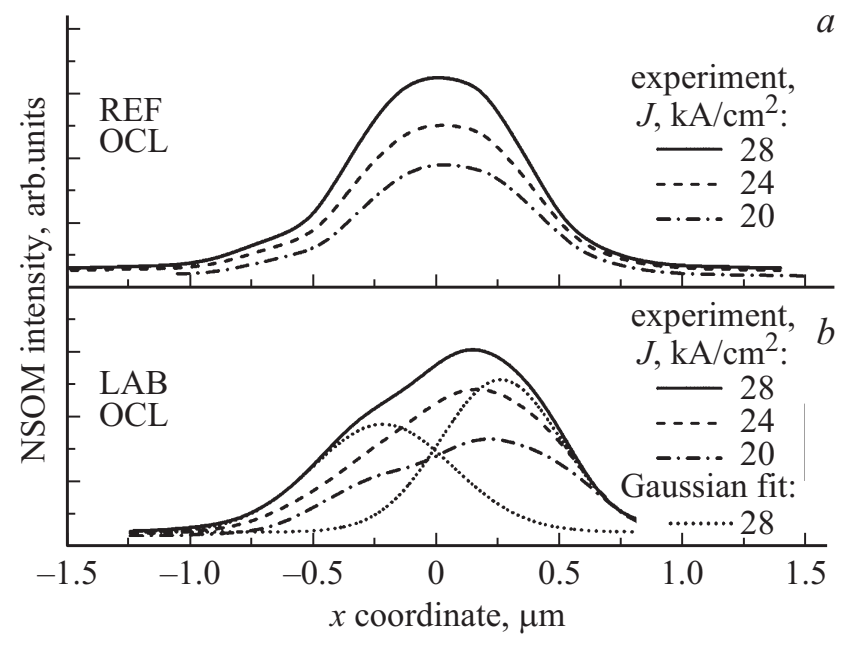

Рис. 6. Профили интенсивности сигнала СБОМ ( $x$-скан) при различных уровнях накачки в спектральном диапазоне волноводной люминесценции для структур $\operatorname{REF}(a)$ и LAB $(b)$. Точечными линиями показано разложение профиля, записанного при накачке 28 кА/ $\mathrm{cm}^{2}$, на две функции Гаусса. 
ты $(0.54 \pm 0.01)$ мкм. Излучение, обусловленное волноводной рекомбинацией, в REF-структуре (рис. 6,a) также имеет максимальную интенсивность в середине волноводного слоя; оно может быть описано функцией Гаусса с полной шириной на половине высоты $(0.75 \pm 0.01)$ мкм.

В отличие от $x$-сканов, обсуждавшихся выше, профиль интенсивности волноводной люминесценции в LAB-структуре (рис. 6, $b$ ) может быть представлен как суперпозиция двух функций Гаусса примерно одинаковой ширины 0.58 мкм, имеющих центры, сдвинутые примерно на $(0.23 \pm 0.01)$ мкм влево и вправо относительно середины волноводного слоя (на рис. $6, b$ проиллюстрировано точечными линиями для плотности тока накачки 28 кА/ $\mathrm{cm}^{2}$ ). При этом интенсивность левого (со стороны $n$-эмиттера) распределения заметно подавлена по отношению к правому (со стороны $p$-эмиттера), так что максимум совокупной интенсивности сдвинут к p-эмиттеру примерно на 0.2 мкм.

\section{5. Обсуждение результатов}

На характер пространственного распределения оптической моды оказывают совместное влияние профили вещественной и мнимой частей показателя преломления. Профиль вещественной части одинаков в обеих исследуемых лазерных структурах и симметричен относительно центра волновода, поскольку вкладом асимметричных барьерных слоев можно пренебречь вследствие их малой толщины. Таким образом, единственной причиной, которая может вызвать искажение оптической моды в LAB-структуре по отношению к REF-структуре, является отличие в них пространственного профиля оптических потерь, которые могут быть связаны с поглощением на свободных носителях и с межзонным поглощением.

Фотоны с длинами волн, соответствующими излучению из квантовой ямы (QW GS и QW ES), не испытывают межзонного поглощения в волноводном слое, а влияние поглощения на свободных носителях мало. На это указывает одинаковый и симметричный профиль интенсивности излучения из квантовой ямы, наблюдаемый в измерениях СБОМ обеих структур. Пространственное распределение фундаментальной $\mathrm{TE}_{0}$-моды с длиной волны $850 \mathrm{Hм}$, рассчитанное для диэлектрического (без потерь) плоского волновода $\mathrm{Al}_{0.2} \mathrm{Ga}_{0.8} \mathrm{As} / \mathrm{Al}_{0.4} \mathrm{Ga}_{0.6} \mathrm{As}$ толщиной 0.8 мкм, показано на рис. 5 точечной линией. Оно обладает пространственной шириной на половине высоты 0.55 мкм, что превосходно согласуется с экспериментальными данными для спектральной компоненты QW GS.

В то же время приближение диэлектрического волновода не дает удовлетворительного согласия с наблюдаемыми профилями СБОМ для волноводной люминесценции (расчетная ширина моды с длиной волны 750 нм составляет 0.52 мкм на половине высоты). Мы полагаем, что это является прямым свидетельством важности эффектов, связанных с межзонным поглощением излучения этого спектрального диапазона в материале волновода. При этом, чем выше электронно-дырочная концентрация в волноводе, тем слабее это поглощение. Если же волновод заполнен носителями заряда неоднородно, меньшие оптические потери и бо́льшая интенсивность оптической моды должны быть в той области, где концентрация носителей заряда выше.

По всей видимости, недостаточная высота потенциального барьера для электронов, формируемого расположенным со стороны $p$-эмиттера барьерным слоем $\mathrm{Al}_{0.42} \mathrm{Ga}_{0.38} \mathrm{In}_{0.2} \mathrm{As}$, в сочетании с его малой толщиной не создают достаточного препятствия для электронов, инжектируемых из $n$-эмиттера. При этом барьерный слой $\mathrm{Ga}_{0.55} \operatorname{In}_{0.45} \mathrm{P}$ создает для дырок потенциальный барьер высотой $>0.2$ эВ. В результате биполярное заполнение левой части волновода подавлено, а его правую часть заполняют как дырки, так и электроны. Именно такая ситуация обсуждалась выше в связи с рис. 1,c. Увеличение волноводной рекомбинации вблизи $p$-эмиттера вызывает рост интенсивности электролюминесценции на соответствующей длине волны в этой части волновода.

\section{6. Заключение}

Нами показано, что интенсивность излучения, связанного с рекомбинацией носителей заряда в волноводном слое лазерной структуры с асимметричными барьерными слоями, распределена неравномерно по лазерному волноводу. Это излучение подавлено в примыкающей к n-эмиттеру области волновода, так что максимум интенсивности сдвинут к $p$-эмиттеру. Такой характер распределения может быть объяснен тем, что барьерный слой GaInP, располагающийся со стороны $n$-эмиттера, препятствует проникновению дырок в эту часть волновода, тогда как барьерный слой AlGaInAs не создает достаточного препятствия для электронов, заполняющих совместно с дырками примыкающую к $p$-эмиттеру часть волновода. Это не позволяет в полной мере реализовать ожидаемые для лазера с асимметричными барьерными слоями улучшения приборных характеристик по отношению к лазеру традиционной конструкции. Использование асимметричных барьерных слоев $\mathrm{AlGaAsSb}$ либо AlGaInAs оптимизированного состава, обеспечивающих более высокий потенциальный барьер для электронов, позволит преодолеть эту трудность. Также мы обнаружили, что для излучения, обусловленного рекомбинацией в активной области, оптические потери в волноводе малы даже при использованных высоких уровнях инжекции и не искажают профиля моды по отношению к ожидаемому для диэлектрического волновода.

Работа выполнена при поддержке Российского научного фонда (проект 14-42-00006 „Новый тип полупроводниковых лазеров с характеристиками, улучшенными за счет использования асимметричных барьеров“). 


\section{Список литературы}

[1] P. Blood, E.D. Fletcher, K. Woodbridge, K.C. Heasman, A.R. Adams. IEEE J. Quant. Electron., 25 (6), 1459 (1989).

[2] H. Kurakake, T. Uchida, T. Yamamoto, T. Higashi, S. Ogita, M. Kobayashi. IEEE J. Select. Topics Quant. Electron., 3 (2), 632 (1997).

[3] L.V. Asryan, S. Luryi. Solid-State Electron., 47, 205 (2003).

[4] A.E. Zhukov, N.V. Kryzhanovskaya, F.I. Zubov, Y.M. Shernyakov, M.V. Maximov, E.S. Semenova, K. Yvind, L.V. Asryan. Appl. Phys. Lett., 100 (2), 021107 (2012).

[5] F.I. Zubov, M.V. Maximov, Yu.M. Shernyakov, N.V. Kryzhanovskaya, E.S. Semenova, K. Yvind, L.V. Asryan, A.E. Zhukov. Electron. Lett., 51 (14), 1106 (2015).

[6] L.V. Asryan, N.V. Kryzhanovskaya, M.V. Maximov, F.I. Zubov, A.E. Zhukov. J. Appl. Phys., 114, 143103 (2013).

[7] Л.В. Асрян, Ф.И. Зубов, Н.В. Крыжановская, М.В. Максимов, А.Е. Жуков. ФТП, 50, 1380 (2016).

[8] С.О. Слипченко, И.С. Шашкин, Л.С. Вавилова, Д.А. Винокуров, А.В. Лютецкий, Н.А. Пихтин, А.А. Подоскин, А.Л. Станкевич, Н.В. Фетисова, И.С. Тарасов. ФТП, 44 (5), 688 (2010).

[9] И.С. Шашкин, Д.А. Винокуров, А.В. Лютецкий, Д.Н. Николаев, Н.А. Пихтин, М.Г. Растегаева, 3.Н. Соколова, С.О. Слипченко, А.Л. Станкевич, В.В. Шамахов, Д.А. Веселов, А.Д. Бондарев, И.С. Тарасов. ФТП, 46 (9), 1230 (2012).

[10] Н.А. Пихтин, А.В. Лютецкий, Д.Н. Николаев, С.О. Слипченко, 3.Н. Соколова, В.В. Шамахов, И.С. Шашкин, А.Д. Бондарев, Л.С. Вавилова, И.С. Тарасов. ФТП, 48 (10), 1377 (2014).

[11] A.V. Ankudinov, M.L. Yanul, S.O. Slipchenko, A.V. Shelaev, P.S. Dorozhkin, A.A. Podoskin, I.S. Tarasov. Opt. Express, 22 (21), 26438 (2014).

[12] А.Е. Жуков, Н.В. Крыжановская, М.В. Максимов, А.Ю. Егоров, М.М. Павлов, Ф.И. Зубов, Л.В. Асрян. ФТП, 45 (4), 540 (2011).

[13] А.Е. Жуков, Л.В. Асрян, Е.С. Семенова, Ф.Е. Зубов, Н.В. Крыжановская, М.В. Максимов. ФТП, 49 (7), 956 (2015).

Редактор Л.В. Шаронова

\section{Peculiarities of waveguide recombination in laser structures with asymmetric barrier layers}

Yu.S. Polubavkina ${ }^{1}$, F.I. Zubov ${ }^{\mathbf{1}, 2}$, E.I. Moiseev' ${ }^{1}$, N.V. Kryzhanovskaya ${ }^{\mathbf{1 , 2}, \text { M.V. Maximov }}{ }^{\mathbf{1 , 2}}$, E.S. Semenova ${ }^{3}$, K. Yvind ${ }^{3}$, L.V. Asryan ${ }^{4}$, A.E. Zhukov ${ }^{1,2}$

${ }^{1}$ St. Petersburg National Research Academic University, Russian Academy of Sciences, 194021 St. Petersburg, Russia

${ }^{2}$ Peter the Great St. Petersburg Polytechnic University, 195251 St. Petersburg, Russia

${ }^{3}$ DTU Fotonik, Technical University of Denmark, Kgs. Lyngby, DK-2800, Denmark

${ }^{4}$ Virginia Polytechnic Institute and State University, Blacksburg, Virginia 24061, USA

Abstract Spatial distribution of intensity of the emission caused by recombination appeared at high injection level (up to $30 \mathrm{kA} / \mathrm{cm}^{2}$ ) in a waveguiding layer of $\mathrm{GaAs} / \mathrm{AlGaAs}$ laser structure with GaInP and AlGaInAs asymmetric barrier layers was studied by means of near-field scanning optical microscopy. It was found that in such laser the waveguide luminescence, which is integrally less intensive as compared to that in a similar laser without asymmetric barriers, is non-uniformly distributed thought the waveguide such that the distribution maximum is shifted closer to a $p$-type doped cladding layer. This can be explained taking into account a capability of the GaInP barrier, which adjoins the quantum well at an $n$-type doped cladding layer side, to suppress hole transport. 